American Journal of Pharmaceutical Education 2019; 83 (10) Article 7877.

\title{
COMMENTARY
}

\section{A Peek Behind the Scenes of the American Journal of Pharmaceutical Education}

\author{
Lauren S. Schlesselman, MA Ed Psych, PharmD, ${ }^{\mathrm{a}, \mathrm{b}}$ Frank Romanelli, PharmD, $\mathrm{MPH}^{\mathrm{c}, \mathrm{d}}$ \\ ${ }^{\text {a }}$ University of Connecticut, Storrs, Connecticut \\ ${ }^{\mathrm{b}}$ Associate Editor, American Journal of Pharmaceutical Education, Arlington, Virginia \\ ${ }^{\mathrm{c}}$ University of Kentucky College of Pharmacy, Lexington, Kentucky \\ ${ }^{\mathrm{d}}$ Executive Associate Editor, American Journal of Pharmaceutical Education, Arlington, Virginia \\ Submitted October 8, 2019; accepted November 4, 2019; published December 2019.
}

Keywords: peer review, service, scholarship

During the Journal's search for a new associate editor, we realized how much of a mystery the editorial process may be to other members of the Academy. As scholarly publication is part of the mission of almost every faculty member, we felt readers might also want to know what goes on behind the scenes between the time of submission and receipt of that muchsought-after acceptance letter, and on to the point of publication.

When a manuscript is submitted, the first step involves a technical check conducted by the Journal staff. Staff members are looking to ensure basic requirements are met, such as use of noncontinuous line numbers, accurate page numbering, and other required formatting as outlined in the instructions for authors. The purpose of the technical check is to ensure manuscripts are in an appropriate and usable format so that editors can begin an initial assessment and assign peer reviewers if the paper merits further consideration.

Following the technical check, the manuscript is either returned to the author for formatting adjustments or, if the manuscript is appropriately formatted, reviewed by the editor-in-chief. The members of the editorial team have a diversity of pharmacy backgrounds with broad research experiences, allowing the editor-in-chief to assign a manuscript to the associate editor whose experience best aligns with the manuscript's topic. The associate editor assigned to handle the manuscript conducts an initial review of the paper to evaluate the appropriateness of the paper for the Journal, quality of the writing, strength of research design and interpretation of results, and duplication of other AJPE articles. About $40 \%$ of

Corresponding Author: Lauren S. Schlesselman, University of Connecticut, 368 Fairfield Way, Unit 4001, Storrs, CT 06268. Tel: 860-486-3402. Email: lauren.schlesselman@uconn.edu. manuscripts fail one or more of these criteria and are rejected without undergoing peer review.

Those manuscripts that pass these initial steps are subsequently sent for peer review. Using the keywords that authors provide for their manuscript, the editor-in-chief or associate editor searches for potential reviewers with similar interests. Typically, 10 to 12 potential reviewers are selected and assigned in a queue fashion to each paper. The first two individuals in the queue are sent a formal invitation to review. These individuals have 7 days to accept or decline the invitation. If they accept, they are given 21 days to submit their review. If they decline or do not respond within 7 days, the system invites the next person in the queue, who is then given 7 days to respond, and so on until two reviewers accept. After time spent waiting for responses, managing declines to review (sometimes as many as $10-15$ per manuscript), and sending reminders to late reviewers, the editorial team often receives a review that is poorly written and/or does not provide adequate guidance to the authors. Thus, the editor-in-chief or associate editor may need to invite additional reviewers to obtain the quality reviews needed to make a decision.

After a manuscript is reviewed by a minimum of two peers, the assigned editor will review the manuscript along with the reviews and decide whether to accept or reject the paper. Accepted papers may require no revisions, minor revisions, or major revisions. As part of the review process, peer reviewers are asked to make recommendations to the assigned editor regarding whether the paper should be accepted or rejected, and the assigned editor may concur with those recommendations or arrive at his/her own conclusions regarding the manuscript. Once a paper is rejected, it is not reconsidered.

If a paper is accepted pending revisions, authors are given a deadline for submission of their revised manuscript, which must be accompanied by a point-by-point 


\section{American Journal of Pharmaceutical Education 2019; 83 (10) Article 7877.}

explanation of the changes made. The revised manuscript is then reconsidered by the assigned editor, who will then make a final decision on the disposition of the paper. Once a paper is accepted, it moves into the publication ahead of print or early release queue. The Journal staff will then lightly format the paper and prepare it for early release publication. All early release papers have not been copyedited yet.

Once the manuscript is scheduled for a regular issue of the Journal, it enters the copyediting stage. The copyeditor reads the manuscript line by line, checking its grammar and readability, and adding queries and suggestions for the corresponding author. The copyedited paper undergoes a final review by either the editor-in-chief or the executive associate editor before it is returned to the corresponding author for requested corrections. The corresponding author is given 2 business days to review the copyedited paper and reply to all editor and copyeditor queries and make any final substantial changes to the paper. Once the corresponding author returns this version of the paper, the editorial manager reviews all changes made to the paper and prepares the paper for production. The production vendor has 5 business days to create the e-proof. The e-proof and copyright transfer form are then sent to the corresponding author, who is given 2 business days to perform a final review of the e-proof before it gets published in a regular issue of the Journal.

The editor-in-chief and associate editors devote numerous hours to the Journal. Why do we volunteer our time? At the heart of our profession is an obligation to serve. Beyond our commitment to serve, we enjoy the reward of working with authors to develop their project and improve their manuscripts as well as the level of scholarship across the Academy. We are also pharmacy geeks who love the chance to read the exciting projects undertaken at various schools of pharmacy. Most importantly, we believe everyone needs to play a role in helping to advance the Journal and the Academy, and this is the role we have volunteered to fulfil.

Despite the rewards of working with authors and advancing the Journal, being an associate editor on the editorial team is not easy. Working with the Journal, you have to have (or quickly develop) a thick skin. The Journal will publish 12 issues per year beginning in 2020 and each issue has approximately 25 articles. In 2018, the Journal received 583 submissions (about twice the number of papers published), making it impossible to accept every paper without creating an extensive backlog of manuscripts. The editorial team has worked diligently to reduce the backlog and we have made significant progress. We have all been on the receiving end of a manuscript rejection, so we sympathize with the disappointment that a rejection letter brings. Even with rejected papers, it is our goal to provide authors with as much constructive feedback as possible in order to strengthen the submitted work for a potential future submission to another journal.

We encourage members of the Academy to volunteer to review for AJPE. When you are selected to review, we ask that you actively participate or, if you are not able to accept the invitation that you expeditiously decline. These small steps hasten the time between submission and first decision for authors.

The Journal remains a vital component of AACP. It allows members to communicate their scholarly work and to learn from and about each other. The editorial team serves the mission of guarding the scholarly integrity of AJPE. We hope that by outlining the processes involved in the cycle of submission to decision, and eventual publication, that we have contributed to the transparency of our work. The Journal is our passion, and we aspire to continue the diligence of our predecessors in making the American Journal of Pharmaceutical Education the premier publication in pharmacy education. 